\title{
Preoperative anemia management in the coronavirus disease (COVID-19) era
}

Seth I. Perelman, MD, FASA, ${ }^{\mathrm{a}}$ Aryeh Shander, MD, FCCM, FCCP, FASA, ${ }^{\mathrm{b}}$ Christian Mabry, MD, ${ }^{\mathrm{a}}$ and Victor A. Ferraris, MD, $\mathrm{PhD}^{\mathrm{c}}$

\section{THE IMPACT OF CORONAVIRUS DISEASE (COVID-19) ON THE BLOOD SUPPLY}

The novel coronavirus, severe acute respiratory syndrome coronavirus 2 (SARS-CoV-2), causes the disease COVID-19 and is responsible for a global pandemic with more than 30,000,000 affected patients worldwide with a significant mortality exceeding $1,000,000 .{ }^{1}$ Certain underserved segments of the population are particularly hard hit, conferring severe risk of exposure and adverse outcomes. ${ }^{2}$ The tragic human toll is unprecedented and resembles the flu epidemic that occurred more than 100 years ago. The current outbreak impacted the global economy and placed a tremendous strain on all health care systems. In addition to its obvious impact on intensive care unit (ICU) beds, ventilators, and personal protective equipment, there are major effects on the supply chain for much-needed supplies to address the pandemic.

The rapid spread of COVID-19 had a profound impact on blood donations, blood supplies, and potentially on blood safety. ${ }^{3}$ The long, possibly asymptomatic incubation period (1-14 days) of COVID-19 has created immense challenges in procuring safe and adequate blood donations. Blood products are a critical component of emergency preparedness. In addition, the implementation of enhanced donor screening, and deferral strategies to maintain a safe donating environment, have limited the donor pool. The nationwide curtailment strategy to limit spread resulted in the cancelling of more than 4000 volunteer blood donation drives, which account for more than $80 \%$ of the blood collected by the American Red Cross, and a deficit of more than 130,000 donations in a few weeks' time. ${ }^{4,5}$ This multifactorial impact on our nation's blood supply led to a call to action from the Director of the US Food

\footnotetext{
From the ${ }^{\mathrm{a}}$ Department of Anesthesiology, Perioperative Care, and Pain Medicine,

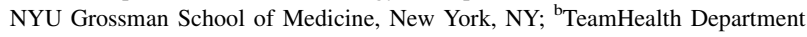
of Anesthesiology, Critical Care and Hyperbaric Medicine, Englewood Health, Englewood, NJ; and ${ }^{\mathrm{c}}$ Department of Cardiothoracic Surgery, University of Kentucky, Lexington VA Medical Center, Lexington, Ky.

Received for publication Dec 21, 2020; accepted for publication Dec 30, 2020; available ahead of print Feb 6, 2021.

Address for reprints: Seth I. Perelman, MD, FASA, 550 First Ave, Tisch 530, New York, NY 10016 (E-mail: Seth.perelman@nyulangone.org).

JTCVS Open 2021;5:85-94

2666-2736

Copyright (C) 2021 The Authors. Published by Elsevier Inc. on behalf of The American Association for Thoracic Surgery. This is an open access article under the CC BY-NCND license (http://creativecommons.org/licenses/by-nc-nd/4.0/).

https://doi.org/10.1016/j.xjon.2020.12.020
}

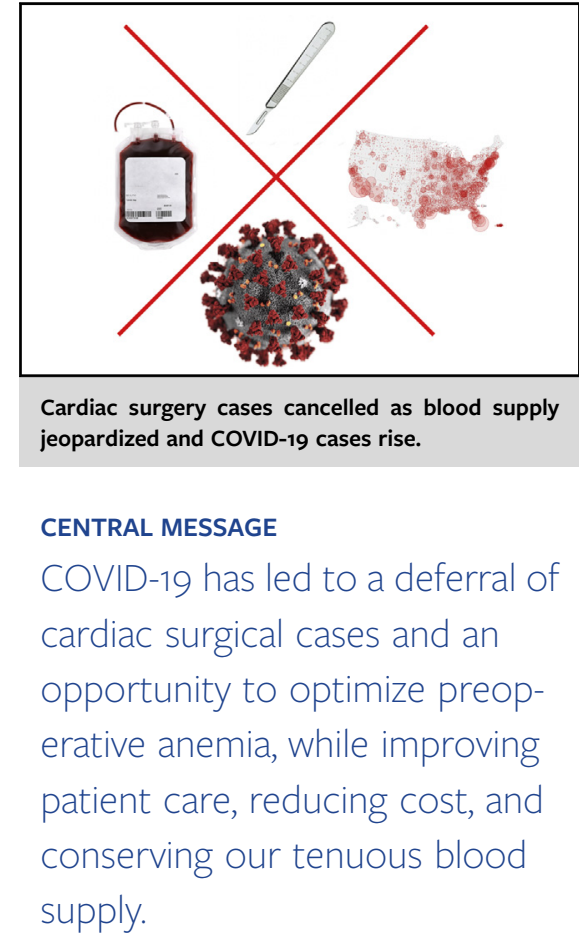

See Commentaries on pages 95 and 97.

and Drug Administration's (FDA) Center for Biologics Evaluation and Research that urged people to start turning out in force to give blood. In an effort to increase the donor pool, the FDA on April 2, 2020, modified certain donor eligibility criteria without compromising the safety of the blood supply. ${ }^{6}$

The declining donor pool is only one factor impacting the national blood supply. Nationwide curtailment strategies also impacted the supply chain of manufacturing supplies needed to maintain blood services. Travel restrictions, factory closings, and decreased manufacturing output will further impact the ability to maintain the blood supply.

\section{RISK OF TRANSMISSION OF COVID-19 FROM DONOR BLOOD PRODUCTS}

While there is no direct evidence that COVID-19, or any other coronaviruses of concern (severe acute respiratory syndrome, Middle East respiratory syndrome coronavirus), can be transmitted through blood or blood components, there is still a theoretical risk of transmission through blood transfusion, especially with a relatively longer 


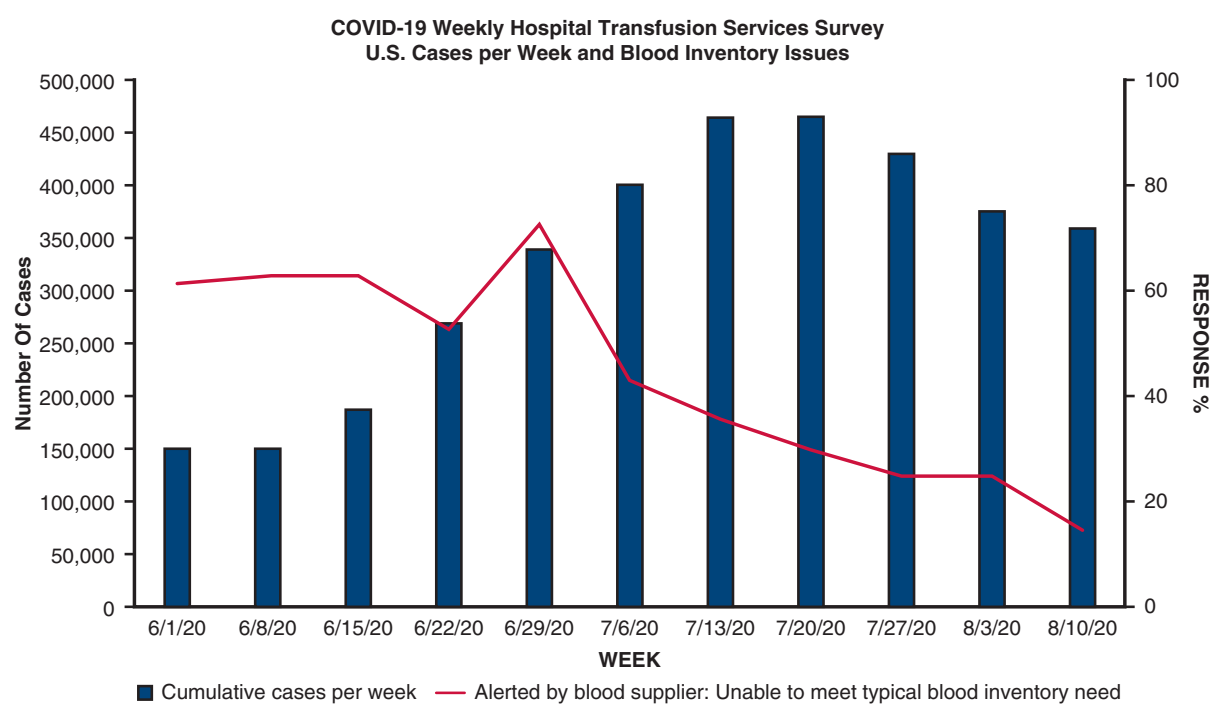

FIGURE 1. AABB COVID-19 weekly US hospital transfusion services survey-week 21, conducted from August 10 to 12,2020 . In total, $14.8 \%$ ( $\mathrm{n}=21$ ) of the hospitals were alerted by their blood supplier that they will not be able to meet typical inventory needs, a decline since survey week 16 (week of July 6 ). O-negative RBCs were the most affected component this week. In total, $48.6 \%$ hospitals have implemented inventory management strategies to deal with the shortages. Data Source: Adapted from AABB weekly survey intended for AABB hospital members. ${ }^{11}$ COVID-19, Coronavirus disesae 2019.

asymptomatic phase. Reports from China show that the detection of viral RNA in the blood of patients infected with COVID-19 is common, but no reports have shown infection of recipients of platelets or red blood cell (RBC) transfusions from donors diagnosed with COVID-19, despite documented examples of transfusion of blood products from infected donors. ${ }^{7}$ In addition, the detection of viral RNA by polymerase chain reaction is not the same as detection of intact live infective virus. ${ }^{8}$ It seems clear that the transfusion dynamics of transmission and infection related to COVID-19 are incompletely understood. ${ }^{9}$

\section{IMPACT OF COVID-19 ON BLOOD SUPPLY}

The challenges faced by the blood bank establishment during the COVID-19 pandemic are to maintain and protect the safety of the blood supply. However, the variables that must be considered and not easily controlled are the use and the demand for blood components. Small studies suggest that the pandemic itself has not resulted in an increased requirement for blood transfusions, especially in patients with mild COVID-19 infection. A small review did show a 36.8\% requirement for packed red blood cell (PRBC) transfusion in patients with COVID-19 in the ICU with lesser requirements for fresh-frozen plasma and platelets, except in the small extracorporeal membrane oxygenation population. ${ }^{10}$ The demand for blood components further decreased in the early stage of the pandemic, by the almost-universal postponing of elective operations, with the net result of lessening the impact on blood inventory. In fact, during early May, greater than $50 \%$ of the respondents to an AABB hospital transfusion services survey reported increased inventory wastage due to the impact of COVID-19, while by June many hospital transfusion services were unable to meet their typical inventory needs from their blood suppliers (Figure 1) and have implemented inventory-management strategies to deal with shortages. ${ }^{11}$

The geographic variation in disease incidence enabled regional redistribution of blood components to areas more profoundly impacted by the decrease in supply. In addition, many transfusion services implemented blood order triage plans to ensure the appropriate use of blood components and considered plans to arbitrarily extend platelet expiration to 7 days from 5 days if necessary. ${ }^{12}$ A recent guideline from the National Blood Transfusion Committee in England proposed a triage tool to guide the ethical allocation of blood components for massive hemorrhage in the setting of severe blood shortage, such as the COVID-19 pandemic. ${ }^{13}$

The greatest concern regarding the impact of COVID-19 on our nation's blood supply revolves around the gradual reopening of society accompanied by the resumption of elective surgery. This increase in surgical volume will likely be accompanied by an increase in blood use, with a delayed replenishment of the blood inventory. Donor recruitment for blood donation will likely be hampered by existing social containment and mitigation policies, potential donor fears, as well as the shift in resources to prioritize convalescent plasma transfusion will continue to impact an already strained inventory. ${ }^{11}$ These concerns occurred in some regions of the nation, where there is currently only a 1- or 2-day supply of blood instead of the usual 1- to 2-week inventory. ${ }^{14}$ Regional voluntary redistribution of blood 
components may alleviate some of the strain, but only to a limited extent, given its short shelf-life. ${ }^{15}$

\section{NATIONAL ORGANIZATION RECOMMENDATIONS}

The impact of COVID-19 on resources required an unprecedented restructuring of health care to continue our commitment to patient care, in addition to planning for the care of all patients in the weeks and months ahead. Many surgical societies developed guidance statements to enable postponing of elective operations during the peak of the pandemic. The rationale for postponing elective operations starting in mid-March 2020 was based on the urgent need to preserve and redirect limited resources and personnel for the treatment of patients with COVID-19. The American College of Surgeons guidance specifically highlighted blood conservation as a key component of this initiative:

- Blood conservation. The nation's blood supply is dropping due to the elimination of blood drives and other factors. Minimizing elective procedures that require blood will help to preserve this resource. ${ }^{14}$

The Society of Thoracic Surgeons (STS) COVID-19 Taskforce and the Workforce for Adult Cardiac and Vascular Surgery released a tiered patient guidance statement to address the changing cardiac surgery landscape, emphasizing the acute needs of the cardiac surgical patient in relation to the prevalence of COVID-19 at their institution. ${ }^{16}$ Ultimately, the prioritization of these goals will maximize the number of lives saved.

The STS database defines operative categories of elective, urgent, and emergent/salvage surgery. These definitions required a re-examination during the COVID-19 era. ${ }^{17}$ While there is an obvious risk in delaying definitive cardiac operations in patients with significant cardiovascular disease, these risks are balanced by the multitude and far-reaching risks of performing surgery during a pandemic. The STS guidance document provides a detailed tiered approach to balancing these factors based on the underlying cardiovascular disease and the impact of COVID-19 on the institution's operative capacity, with the flexibility to adapt to the dynamic landscape of the pandemic and unique patients' needs. ${ }^{16}$ George and colleagues ${ }^{18}$ created their own classification to time cardiac surgery during the pandemic depending on case type and urgency.

\section{PREOPERATIVE ANEMIA IN THE COVID-19 ERA}

This balancing act of risk versus benefit is not necessarily a new paradigm shift for the physician/surgeon, who must constantly balance the risk and timing of an intervention versus delaying a procedure to further optimize a patient before surgery. One important risk factor that is often dismissed before surgery is preoperative anemia. Perioperative anemia is a common condition, present in up to $40 \%$ of patients, and associated with a nearly 5 -fold increase in the odds of postoperative mortality. ${ }^{19}$ It is often considered an abnormal laboratory value that can easily be corrected with a blood transfusion. However, preoperative anemia is an important independent risk factor for perioperative morbidity and mortality in cardiac surgery, and this risk is exacerbated by the current default treatment of allogenic transfusion..$^{20}$ This is especially pertinent as our nation's blood supply is at a critical inventory level, but is also an opportunity to improve patient outcomes by incorporating patient blood management (PBM) strategies for anemia management into our daily cardiac surgery practice. PBM is defined by Society for the Advancement of Blood Management as the timely application of evidence-based medical and surgical concepts designed to maintain hemoglobin (Hgb) concentration, optimize hemostasis, and minimize blood loss to improve patient outcome. ${ }^{21}$ This initiative to address preoperative anemia, a cornerstone of PBM, is not new, and numerous societies support the importance of the identification and management of preoperative anemia, ${ }^{22,23}$ especially during a pandemic. ${ }^{5}$ In fact, Muñoz and colleagues,${ }^{24}$ in their international consensus statement on perioperative management of anemia and iron deficiency, advocated that major nonurgent surgery should be postponed to allow the diagnosis and treatment of anemia and iron deficiency.

Muñoz and colleagues ${ }^{25}$ estimated the prevalence of preoperative anemia at $36.5 \%$ in patients undergoing elective cardiac surgery, and Klein and colleagues ${ }^{26}$ found the incidence among more than 19,000 patients undergoing cardiac surgery in the United Kingdom to be $31 \%$ and independently associated with worse outcomes, including ICU, hospital length of stay, and mortality. Karski and colleagues ${ }^{27}$ found irondeficiency anemia to be the second most common cause of anemia following hospital-acquired anemia in cardiac surgery patients, whereas folate deficiency was present in less than $5 \%$ of the patients and vitamin $B_{12}$ is relatively uncommon worldwide. Deficiencies in vitamin $\mathrm{B}_{12}$ or folate should be treated if identified, and empiric supplementation of vitamin $\mathrm{B}_{12}$ and folate were part of a recent protocol managing iron deficiency anemia in preoperative cardiac surgery patients. ${ }^{28}$ A more recent meta-analysis confirmed that patients with anemia received more transfusions than patients without anemia and that preoperative anemia was associated with an increased risk of stroke, acute kidney injury, infection, and other complications. ${ }^{20,29-36}$

In a recent study by LaPar and colleagues, ${ }^{37} 33,411$ patients undergoing coronary artery bypass grafting $(\mathrm{CABG})$ were investigated to determine the relative association between preoperative hematocrit (Hct) level versus PRBC transfusion on postoperative outcomes. After risk adjustment, PRBC transfusion demonstrated stronger associations with postoperative mortality (odds ratio [OR]; 4.3, 
$P<.0001)$, renal failure (OR, 6.3; $P<.0001)$, and stroke (OR, 2.4; $P<.0001)$. A 1 -point increase in preoperative Hct was associated with a decreased probability of mortality (OR, 0.97; $P=.0001)$ and renal failure (OR, 0.94; $P<.0001)$ and, as expected, a strong association was observed between preoperative Hct and the likelihood for PRBC transfusion $(P<.001) .{ }^{37}$ An editorial by Gaetano Paone $^{38}$ on this study simply stated that "anemia is bad, transfusion is worse, and both together are worse than either one alone," and the real emphasis should be on avoiding the conditions that lead to transfusion.

The challenge to patient outcome is to sort out the relative contributions of preoperative, intraoperative, and postoperative anemia, in addition to the additive risk of RBC transfusion. While the exact etiologies of the adverse effects of transfusion and anemia are not clear, the evidence that transfusion in the cardiac surgical population is not benign and should be used cautiously is clear. These challenges remain in the era of COVID-19 and require additional investigation. ${ }^{36}$ It is clear that preoperative anemia places cardiac surgical patients at a greater risk of postoperative adverse outcomes. ${ }^{39}$ The fact that preoperative anemia is one of the few potentially modifiable risk factors should trigger efforts to optimize Hgb preoperatively. It is likely that preoperative Hgb levels should be included in future risk models such as the European System for Cardiac Operative Risk Evaluation and the STS Predicted Risk of Mortality.

In addition to improvements in postoperative patient outcome, there may be short-term benefits to the evaluation and treatment of anemia as seen in the heart failure and chronic kidney disease population. ${ }^{40,41}$ A 2019 metaanalysis that included 10 randomized controlled trials (RCTs) of patients with heart failure and iron-deficiency anemia had improvements in New York Heart Association class, reduced hospitalizations, improved exercise tolerance, left ventricular ejection fraction, and serum markers of heart failure and inflammation. ${ }^{42}$

It must be emphasized that preoperative anemia management is a multifaceted paradigm that entails a combination of red cell enhancement, careful evaluation of anemia etiologies, and thoughtful intraoperative and postoperative management. Focus on a single strategy to the exclusion of a multifaceted approach is insufficient and lacks evidence base. ${ }^{43}$ Evidence-based findings suggest that preoperative anemia is associated with adverse outcomes from cardiac operations ${ }^{29}$ and in noncardiac surgery, evidence for parenteral iron administration in patients with absolute and functional iron deficiency or anemia is stronger. ${ }^{44-47}$ However, the evidence base for delaying surgery for preoperative treatment of anemia to improve cardiac surgical outcomes is confusing. A Cochrane review looked at the use of iron supplementation in anemic patients before surgery and suggested that the preoperative use of iron supplementation did not show a clinically significant reduction in the proportion of trial participants who received an allogeneic blood transfusion compared to no iron therapy. However, the quality of the evidence was low and the researchers commented that future higher quality of evidence will likely change the results of their review. ${ }^{48}$

Recently, the long-awaited PREVENTT (Preoperative Intravenous Iron to Treat Anaemia before major abdominal surgery) trial, an RCT of intravenous (IV) iron supplementation versus placebo in patients $(\mathrm{n}=487)$ undergoing major abdominal surgery, failed to show that IV iron was superior to placebo at improving outcomes, and there was no statistical difference in the primary outcome of transfusion reduction and avoidance. ${ }^{49}$ However, there was a significant reduction in readmission rates in the IV iron group in the first 8 weeks after surgery. Analysis of the study data revealed some major limitations that make the conclusion and recommendations doubtful. While all patients in the study were anemic, only a fraction had iron-deficiency anemia $(<30 \%)$ and $20 \%$ of the patients in each arm were receiving oral iron, which may explain the increase in $\mathrm{Hgb}$ in the placebo group. The majority of the patients were from a cancer institute, which is not the best cross population sample. Notably absent was any reporting of hemodynamic data, surgical blood loss, transfusion threshold, and with a transfusion rate approaching $30 \%$ would imply a liberal threshold. In addition, despite an increase and greater $\mathrm{Hgb}$ in the IV iron group throughout the trial, it is difficult to reconcile the similar transfusion rates. At this point, it would be premature to discard preoperative anemia management as a useful strategy for PBM based on a single RCT with many limitations.

While the current published evidence is of low quality and too heterogenous, there is evidence that the supplementation with IV iron with or without erythropoietin (EPO) may offer benefit, ${ }^{50,51}$ and the absence of data should not be the reason to neglect preoperative anemia. Even in the setting of urgent cardiac surgery, anemic patients should still receive ultra-short-term therapy. ${ }^{28,43}$ More definitive trials, such as the ITACS (Intravenous Iron for Treatment of Anaemia Before Cardiac Surgery; clinicaltrials.gov NCT02632760) and CAVIAR (UK Cardiac and Vascular Surgery Interventional Anaemia Response $)^{52}$ trials are ongoing and will evaluate the impact of anemia, its management, and outcome in cardiac surgical patients, and we look forward to their findings.

The use of EPO-stimulating agents remains controversial, despite FDA indications for its use in chronic kidney disease, HIV-associated anemia, chemotherapy-induced anemia, and before major elective noncardiac, nonvascular surgery. Many studies show its efficacy and safety with or without IV iron before cardiac surgery in reducing allogeneic transfusion ${ }^{28,50,53-55}$; however, its use remains offlabel because of concerns of thrombosis and mortality. ${ }^{56}$ Even major society guidelines have differing 
recommendations regarding its use and safety. The 2017 European Association for Cardio-Thoracic Surgery/European Association of Cardiothoracic Anaesthesiology Guidelines on PBM for adult cardiac surgery recommend that EPO with or without iron supplementation should be considered in patients with non-iron deficiency undergoing elective surgery to reduce postoperative transfusions. ${ }^{57}$ The 2011 Update to the STS/Society of Cardiovascular Anesthesiologists Blood Conservation Clinical Practice Guidelines states that EPO use should be considered in preoperative anemia but cautions its use for CABG with unstable symptoms because of its thrombotic risks, ${ }^{22}$ whereas the NICE (National Institute for Health and Care Excellence) Guidelines from 2015 do not recommend treatment of preoperative anemia with EPO unless the appropriate blood type is not available or if the patient declines to accept a transfusion. ${ }^{56}$

It is probable that preoperative anemia treatment involves a comprehensive approach to anemia management that entails more than iron supplementation (eg, additional necessary tests include serum iron, ferritin, and transferrin saturation and tests for markers of inflammation). Although there is good evidence that preoperative anemia is associated with adverse cardiac surgical outcomes, the management of this anemia to reduce these adverse outcomes is less well defined. In addition, although we cannot conclude that preoperative anemia per se causes adverse outcomes, this population represents a large cohort of patients globally and the potential implications of reducing major adverse postoperative complications makes the treatment of preoperative anemia a logical imperative and an important area for further research. ${ }^{26}$

Preoperative anemia management in cardiac surgery suggests benefit, but implementation and adoption of practice guidelines have not been straightforward and are made even worse in the era of COVID-19 infection. In one benchmark study, the incidence of preoperative anemia was 3 times greater in patients who were transfused than in patients who were not transfused intraoperatively or postoperatively. In a follow-up study, 99\% of patients with preoperative anemia undergoing $\mathrm{CABG}$ were not treated for their anemia. ${ }^{58,59}$

\section{BARRIERS TO PREOPERATIVE ANEMIA MANAGEMENT}

A theoretical framework identified 3 thematic barriers to guideline adherence: knowledge, attitude, and behavior. ${ }^{60}$ Muñoz and colleagues ${ }^{61}$ specifically examined overcoming the barriers to preoperative Hgb optimization in surgical patients. They addressed many of the misconceptions regarding the indiscriminate transfusion of allogeneic blood as a "quick fix" for preoperative anemia and called for abandoning allogeneic transfusion as an acceptable outcome when preoperative anemia is often ignored. Although strong leadership is a prerequisite, the most important strategy seems to be the timely detection and management of preoperative anemia.

Timely detection of preoperative anemia has always been one of the greatest barriers to preoperative anemia management in the cardiac surgical patient. Despite recent evidence that even ultra-short-term iron deficiency anemia treatment resulted in a reduction in allogeneic blood component transfusion (RBC), ${ }^{28}$ at least 3 weeks is ideally needed to treat iron-deficiency anemia. Often there is ample time to screen for anemia but it is rarely performed despite STS guidelines recommending evaluation of iron status before major surgery. ${ }^{14}$ The additional necessary tests, like serum iron, ferritin, transferrin saturation, and markers of inflammation, are low cost and readily available and are part of proper preoperative risk stratification and reduction. What might be considered postponing surgery is actually working within the timeframe of initial consultation, scheduling, and date of surgery for most cardiac surgical operations. In the setting of unexpected preoperative anemia, delaying a scheduled case would be an appropriate indication for any surgical procedure with anticipated moderate-to-high blood loss. ${ }^{61}$

The STS National Cardiac Surgery Database defines an elective operation as one that is performed on a patient with cardiac function who has been stable in the days or weeks before operation. Interestingly, in their definition of urgent, which would advocate for surgery within 24 hours to prevent clinical deterioration, they state that surgery may be delayed by attempts to improve the patient's condition. Left main disease alone, use of a heparin infusion, or purely administrative conditions do not merit categorizing a patient as urgent. In either scenario, elective or urgent, there is an opportunity to identify the etiology of preoperative anemia and initiate therapy.

\section{COVID-19-RELATED DELAYS IN OPERATIONS}

The impact of the COVID-19 pandemic affected cardiac surgical volume and many patients' surgeries have been delayed weeks to months. At NYU Langone Health, cardiac surgical volume was decreased by $40 \%$ and greater than $90 \%$ in March and April, 2020 respectively, and this is similar to nationwide and regional data from the United States. The COVID-19 North American Cardiac Survey Working Group surveyed 67 adult cardiac surgery programs across North America, representing an annualized case volume of 60,452 in 2019 and found a $45 \%$ decline in cases in $96 \%$ of the centers, with a relative decrease in valvular cases compared with a relative increase in CABG surgery during the first wave of the pandemic. ${ }^{62}$ In another worldwide survey among 60 centers in March 2020, there was a mean reduction in cardiac surgery volume of $50 \%$ to $75 \%$, corresponding to regional COVID-19 cases. ${ }^{63}$ What is currently unknown is the impact on patient outcome 


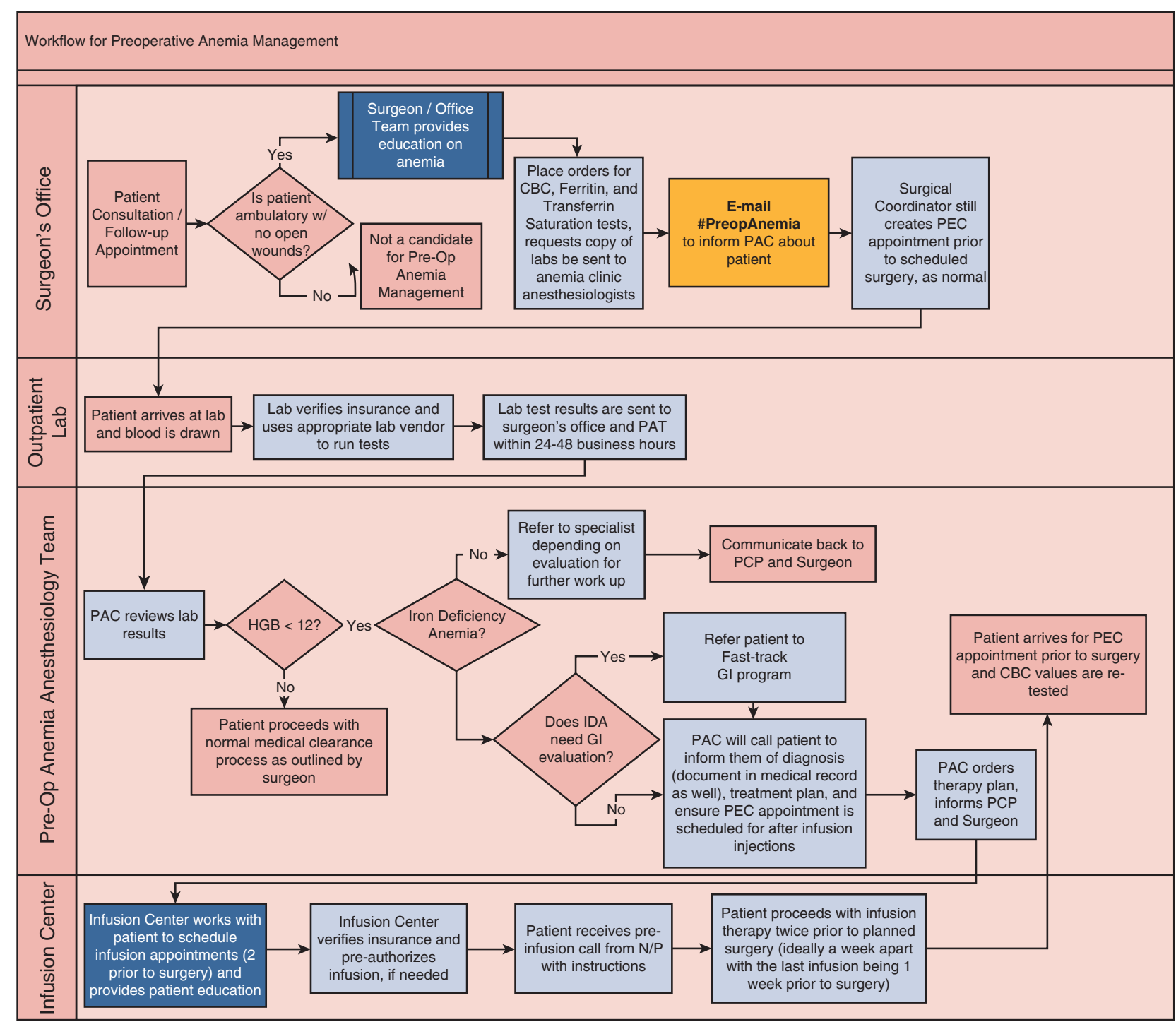

FIGURE 2. Preoperative anemia clinic workflow. Shown is an algorithm for identification, evaluation, and management of preoperative anemia in setting of planned elective surgery. $C B C$, Complete blood count; $P A C$, preoperative anemia clinic; $P E C$, preoperative evaluation clinic; $P A T$, preadmission testing; $H g b$, hemoglobin; IDA, iron-deficiency anemia; $G I$, gastroenterology; $P C P$, primary care physician; $N P$, nurse practitioner.

from these delays in surgery in the wake of the pandemic. What is clear is that there may not be a significant impact on outcome from delaying elective operations based on experience from Canada and the United Kingdom, where postponements of elective cardiac operations are routine and delays may be prolonged (as long as 3 months) but are not necessarily associated with worse patient outcomes in the short term. ${ }^{64,65}$ Data for the United Kingdom from 2017/2018 reveal mean wait times of 96 days for elective $\mathrm{CABG}$, more than ample time to evaluate and treat preoperative anemia. ${ }^{66}$ Morgan and colleagues, ${ }^{67}$ analyzing a large Canadian database of CABG patients, reported an average waiting time of 38 days with a $0.4 \%$ mortality of patients waiting. However, long waiting lists for $\mathrm{CABG}$ are associated with increased mortality, and individual independent risk factors, such as impaired left ventricular function, unstable angina, perioperative risk, and concomitant aortic valve disease, should be considered at initial evaluation. ${ }^{67,68}$ Severe symptomatic aortic stenosis is associated with high mortality without intervention, but even asymptomatic severe aortic stenosis is associated with increasing mortality with treatment delay and delays beyond 1 month should be avoided. ${ }^{69}$ However, there is an opportunity to identify and mange anemia in the large cohort of elective cardiac surgery patients who present with preoperative anemia. A similar risk stratified queuing process can be used to determine which patients can have their surgery deferred for preoperative IV iron supplementation and which patients 
may benefit from an ultra-short-term anemia management. ${ }^{64,68}$

\section{IDEALIZED PREOPERATIVE MANAGEMENT IN THE COVID-19 ERA}

With the uprooting of "normal" medical surgical management as seen with this pandemic, the delay in elective operations should result in an orchestrated mechanism for regular communication to monitor for progression of symptoms, given the dynamic nature of cardiovascular disease, while addressing all modifiable risks including anemia. ${ }^{16}$ The pandemic has clearly shown the vulnerabilities of our health care system, especially our perceived stable blood supply. It has shown us that there is time, time to reflect on cultural norms and look for opportunities to implement change to improve patient outcome. And, most importantly, there is the time to address preoperatively modifiable risk factors, such as iron deficiency and iron-deficiency anemia in the cardiac surgical patient. There are anticipated benefits from these time-sensitive interventions that will likely improve patient care, reduce cost, and conserve a tenuous but vital blood supply.

A major barrier to the management of preoperative anemia in cardiac surgery has been the absence of a preoperative anemia clinic or other pathways to facilitate the coordination and care of the anemic patient. Models that depend on a free-standing preoperative anemia clinic can be cost prohibitive and may not have the required endorsement of the hospital administration, a necessary ingredient for success.

At NYU Langone Medical Center, consideration of various models for preoperative anemia management led to creation of a preoperative anemia clinic using a minimal staffing model under the direction of an anesthesiologist. The Clinic's role is to coordinate the identification and treatment of preoperative iron-deficiency anemia through a combination of chart and laboratory review, phone consultation, and scheduling through an infusion center (Figure $2^{70}$ ). Additional safety requirements during the COVID-19 pandemic include preoperative screening, social distancing in health care encounters, and the incorporation of telemedicine visits when appropriate. In our first phase, focusing on gynecologic, spine, and general surgery patients, we have been able to increase Hgb values on average by $2 \mathrm{~g} / \mathrm{dL}$ in more than 100 patients. $^{70}$ The majority of the patients were treated with IV iron and a few, because of the severity of anemia or urgency of surgery, received EPOstimulating agents as well. Newer formulations of IV iron have allowed for the rapid repletion of iron deficits with short convenient infusions and improved safety. ${ }^{71-75}$

Anticipating barriers and obstacles to implementation of a preoperative anemia clinic, some of which may be institution specific, facilitates successful implementation and cultural acceptance (Tables 1 and 2). In a recent UK national
TABLE 1. Potential barriers to evaluate and manage preoperative anemia

\begin{tabular}{|c|c|}
\hline Barrier & Solution \\
\hline $\begin{array}{l}\text { Lack of knowledge about risks of } \\
\text { IDA and blood safety }\end{array}$ & $\begin{array}{l}\text { Multidisciplinary evidence-based } \\
\text { PBM educational initiatives. }\end{array}$ \\
\hline $\begin{array}{l}\text { Inefficient workflow for blood } \\
\text { management implementation }\end{array}$ & $\begin{array}{l}\text { OR scheduling limitations. A } \\
\text { workflow for preoperative } \\
\text { patient optimization must } \\
\text { conform to the existing } \\
\text { operating room scheduling } \\
\text { process to maximize "buy-in" } \\
\text { from surgical service. }\end{array}$ \\
\hline Organizational constraints & $\begin{array}{l}\text { Executive leadership support and } \\
\text { designated "patient blood } \\
\text { manager" to centralize decision } \\
\text { making processes. }\end{array}$ \\
\hline $\begin{array}{l}\text { Administrative/surgical/ } \\
\text { hematology support }\end{array}$ & $\begin{array}{l}\text { All services must support the } \\
\text { patient blood management } \\
\text { program. A PBM program } \\
\text { relies on several subspecialties } \\
\text { for referrals, implementation, } \\
\text { and follow-up. }\end{array}$ \\
\hline Laboratory constraints & $\begin{array}{l}\text { Central laboratory must be able to } \\
\text { perform the necessary tests to } \\
\text { efficiently diagnosis the type of } \\
\text { anemia. "Reflex" order sets can } \\
\text { streamline this process so that } \\
\text { only an abnormal result triggers } \\
\text { further anemia evaluation. }\end{array}$ \\
\hline Lack of infusion center resources & $\begin{array}{l}\text { Use existing infusion center } \\
\text { resources to administer IV iron. }\end{array}$ \\
\hline $\begin{array}{l}\text { Availability of low labile iron } \\
\text { preparations }\end{array}$ & $\begin{array}{l}\text { Formulations of IV iron (low } \\
\text { labile iron content) allow for } \\
\text { rapid administration. } \\
\text { Accessibility to these } \\
\text { formulations greatly } \\
\text { streamlines the process. }\end{array}$ \\
\hline Lack of process familiarity & $\begin{array}{l}\text { Efficient streamlined workflow } \\
\text { and process to initiate anemia } \\
\text { evaluation. Support staff } \\
\text { (licensed independent } \\
\text { practitioners) commonly } \\
\text { needed. }\end{array}$ \\
\hline
\end{tabular}

Identification of knowledge, resources, and institutional barriers is crucial to the successful evaluation and management of preoperative anemia. IDA, Iron-deficiency anemia; $P B M$, patient blood management; $O R$, operating room; $I V$, intravenous.

initiative study in cardiac surgery, the feasibility and effectiveness of introducing a preoperative IV iron service was assessed. Seven of 11 National Health Service hospitals set up clinics over a 2-year period and 228 patients were recruited. IV iron was administered a median of 33 days preoperatively with an increase in $\mathrm{Hgb}$ from baseline. ${ }^{76}$ Additional adequately powered studies are needed to assess the clinical effectiveness on patient outcomes. While the 
TABLE 2. Potential barriers after implementation of a preoperative anemia clinic

\begin{tabular}{cc}
\hline \multicolumn{1}{c}{ Barrier } & \multicolumn{1}{c}{ Solution } \\
\hline $\begin{array}{c}\text { Provider unwilling to } \\
\text { postpone operation }\end{array}$ & $\begin{array}{c}\text { Preoperative anemia management may } \\
\text { take weeks. Provider must be willing to } \\
\text { postpone surgery when safe. Perceived } \\
\text { urgency is not always evidence-based. } \\
\text { Patient appreciation of preoperative } \\
\text { risk-reduction strategy. }\end{array}$ \\
$\begin{array}{c}\text { Insurance precertification and } \\
\text { transparency before iron infusions sets } \\
\text { the financial expectations for both the } \\
\text { institution and patient. }\end{array}$ \\
$\begin{array}{c}\text { Fatient inconvenience } \\
\text { (extra trip, infusion } \\
\text { center proximity) }\end{array}$ \\
$\begin{array}{c}\text { Adverse reactions to iron the benefits to offset perceived } \\
\text { infusion }\end{array}$ & $\begin{array}{c}\text { Nausea and vasovagal-like reactions are } \\
\text { the most common side effects to } \\
\text { intravenous iron. Although rarely life } \\
\text { threatening, providers should have a }\end{array}$ \\
plan for when these occur.
\end{tabular}

Barriers and solutions for the successful implementation of a preoperative anemia clinic are shown.

presence of a preoperative anemia clinic facilitates and standardizes anemia management, it is by no means a prerequisite to identify, evaluate, and treat the modifiable risk factor, preoperative anemia.

\section{SUMMARY}

While the focus of this review is on preoperative anemia management, a modifiable risk factor and the cornerstone of PBM, the importance of other allogeneic components on adverse outcomes and the impact of the pandemic on their availability, especially platelets with their short shelf life, should not be minimized. The implementation of a multidisciplinary PBM program with an emphasis on meticulous surgical and perioperative hemostasis will contribute to decreased allogeneic component utilization with improved patient outcomes. Cardiac surgery PBM initiatives should include the identification of patients at high risk of bleeding, minimizing intraoperative hemodilution, maintaining normothermia, prevention of fibrinolysis, individual heparin/protamine titration, use of cell salvage, and perioperative treatment algorithms for bleeding patients. ${ }^{5}$

The COVID-19 epidemic created a dramatic shift in patient triage and in the use of surgical resources. The epidemic-related changes to blood supply, and transfusion needs offers multiple opportunities and challenges for transfusion decisions and for management of blood resources.
Limited early experience suggests several features associated with blood resource management during the pandemic. Delays in timing of operations offers an ideal opportunity to improve coagulation parameters and optimize RBC levels. Improving preoperative patient profiles includes a multifaceted approach to risk assessment and careful triage. A preoperative anemia clinic can help in this process. The uncertain duration of this pandemic, and the likelihood of future pandemics, makes it necessary to implement pandemic-specific interventions that may not have robust evidence but are supported by short-term experience and observational data. These alternatives offer the best options for management until a larger more robust evidence base is accrued.

\section{Conflict of Interest Statement}

Dr Shander has received funding from Masimo, CSL Behring, Pharmacosmos, and Daiichi-Sankyo, which are unrelated to the submitted work but may contain relevant conflicts of interest. All other authors reported no conflicts of interest.

The Journal policy requires editors and reviewers to disclose conflicts of interest and to decline handling or reviewing manuscripts for which they may have a conflict of interest. The editors and reviewers of this article have no conflicts of interest.

\section{References}

1. An interactive web-based dashboard to track COVID-19 in real time. 2020. Available at: https://coronavirus.jhu.edu/map.html. Accessed September 25, 2020.

2. Mendy A, Apewokin S, Wells AA, Morrow AL. Factors associated with hospitalization and disease severity in a racially and ethnically diverse population of COVID-19 patients. medRxiv. June 17, 2020. https://doi.org/10.1101/2020. 06.25.20137323 [Epub ahead of print].

3. Cai X, Ren M, Chen F, Li L, Lei H, Wang X. Blood transfusion during the COVID-19 outbreak. Blood Transfus. 2020;18:79-82.

4. Raturi M, Kusum A. The active role of a blood center in outpacing the transfusion transmission of COVID-19. Transfus Clin Biol. 2020;27:96-7.

5. Shander A, Goobie SM, Warner MA, Aapro M, Bisbe E, Perez-Calatayud AA, et al. The essential role of patient blood management in a pandemic: a call for action. Anesth Analg. 2020;131:74-85.

6. Coronavirus (COVID-19) update: FDA provides updated guidance to address the urgent need for blood during the pandemic. 2020. Available at: https://www.fda. gov/news-events/press-announcements/coronavirus-covid-19-update-fda-providesupdated-guidance-address-urgent-need-blood-during-pandemic. Accessed August 20, 2020.

7. Cho HJ, Koo JW, Roh SK, Kim YK, Suh JS, Moon JH, et al. COVID-19 transmission and blood transfusion: a case report. J Infect Public Health. 2020;13: 1678-9.

8. Chang L, Yan Y, Wang L. Coronavirus disease 2019: coronaviruses and blood safety. Transfus Med Rev. 2020;34:75-80.

9. Stanworth SJ, New HV, Apelseth TO, Brunskill S, Cardigan R, Doree C, et al. Effects of the COVID-19 pandemic on supply and use of blood for transfusion. Lancet Haematol. 2020;7:e756-64.

10. Fan BE, Ong KH, Chan SSW, Young BE, Chong VCL, Chen SPC, et al. Blood and blood product use during COVID-19 infection. Am J Hematol. 2020;95: E158-60.

11. AABB COVID-19 weekly hospital transfusion services survey: week 21 snapshot. 2020. Available at: http://www.aabb.org/advocacy/regulatorygovernment/ Documents/AABB-COVID-19-Impact-Survey-Snapshot.pdf. Accessed August 22, 2020. 
12. Pagano MB, Hess JR, Tsang HC, Staley E, Gernsheimer T, Sen N, et al. Prepare to adapt: blood supply and transfusion support during the first 2 weeks of the 2019 novel coronavirus (COVID-19) pandemic affecting Washington State. Transfusion. 2020;60:908-11.

13. Doughty H, Green L, Callum J, Murphy MF, National Blood Transfusion Committee. Triage tool for the rationing of blood for massively bleeding patients during a severe national blood shortage: guidance from the National Blood Transfusion Committee. Br J Haematol. 2020;191:340-6.

14. COVID-19 pandemic leading to blood supply shortages. Transfusion news; 2020. Available at: https://transfusionnews.com/2020/03/17/covid-19-pandemic-leading-to-blood-supply-shortages/. Accessed May 16, 2020.

15. Sussman JS. Coronavirus disease 2019 (COVID-19) poses challenges for the U.S. blood supply. Congressional research service 2020; 2020. Available at: https:// crsreports.congress.gov/product/pdf/IN/IN11238. Accessed May 16, 2020.

16. Haft JW, Atluri P, Alawadi G, Engelman DT, Grant MC, Hassan A, et al. Adult cardiac surgery during the COVID-19 pandemic: a tiered patient triage guidance statement. Ann Thorac Surg. 2020;110:697-700.

17. Clark RE. The Society of Thoracic Surgeons national database status report. Ann Thorac Surg. 1994;57:20-6.

18. George I, Salna M, Kobsa S, Deroo S, Kriegel J, Blitzer D, et al. The rapid transformation of cardiac surgery practice in the coronavirus disease 2019 (COVID19) pandemic: insights and clinical strategies from a center at the epicenter. Ann Thorac Surg. 2020;110:1108-18.

19. Beattie WS, Karkouti K, Wijeysundera DN, Tait G. Risk associated with preoperative anemia in noncardiac surgery: a single-center cohort study. Anesthesiology. 2009; 110:574-81.

20. Karkouti K, Wijeysundera DN, Beattie WS. Reducing bleeding in cardiac surgery. I. Risk associated with preoperative anemia in cardiac surgery: a multicenter cohort study. Circulation. 2008;117:478-84.

21. Frietsch T, Shander A, Faraoni D, Hardy JF. Patient blood management is not about blood transfusion: it is about patients' outcomes. Blood Transfus. 2019; 17:331-3.

22. Society of Thoracic Surgeons Blood Conservation Guideline Task Force, Ferraris VA, Brown JR, Despotis GJ, Hammon JW, Reece TB, et al. 2011 update to the Society of Thoracic Surgeons and the Society of Cardiovascular Anesthesiologists blood conservation clinical practice guidelines. Ann Thorac Surg. 2011;91:944-82.

23. Raphael J, Mazer CD, Subramani S, Schroeder A, Abdalla M, Ferreira R, et al. Society of Cardiovascular Anesthesiologists Clinical practice improvement advisory for management of perioperative bleeding and hemostasis in cardiac surgery patients. Anesth Analg. 2019;129:1209-21.

24. Munoz M, Acheson AG, Auerbach M, Besser M, Habler O, Kehlet H, et al. International consensus statement on the peri-operative management of anaemia and iron deficiency. Anaesthesia. 2017;72:233-47.

25. Muñoz M, Ariza D, Gómez-Ramírez S. Preoperative anemia in elective cardiac surgery: prevalence, risk factors, and influence on postoperative outcome. Transfus Altern Transfus Med. 2010;11:47-56.

26. Klein AA, Collier TJ, Brar MS, Evans C, Hallward G, Fletcher SN, et al. The incidence and importance of anaemia in patients undergoing cardiac surgery in the UK - the first Association of Cardiothoracic Anaesthetists national audit. Anaesthesia. 2016;71:627-35.

27. Karski JM, Mathieu M, Cheng D, Carroll J, Scott GJ. Etiology of preoperative anemia in patients undergoing scheduled cardiac surgery. Can J Anaesth. 1999;46:979-82.

28. Spahn DR, Schoenrath F, Spahn GH, Seifert B, Stein P, Theusinger OM, et al. Effect of ultra-short-term treatment of patients with iron deficiency or anaemia undergoing cardiac surgery: a prospective randomised trial. Lancet. 2019;393: 2201-12.

29. Padmanabhan H, Siau K, Curtis J, Ng A, Menon S, Luckraz H, et al. Preoperative anemia and outcomes in cardiovascular surgery: systematic review and metaanalysis. Ann Thorac Surg. 2019;108:1840-8.

30. Hung M, Besser M, Sharples LD, Nair SK, Klein AA. The prevalence and association with transfusion, intensive care unit stay and mortality of preoperative anaemia in a cohort of cardiac surgery patients. Anaesthesia. 2011; 66:812-8.

31. Kulier A, Levin J, Moser R, Rumpold-Seitlinger G, Tudor IC, SnyderRamos SA, et al. Impact of preoperative anemia on outcome in patients undergoing coronary artery bypass graft surgery. Circulation. 2007;116: 471-9.

32. van Straten AH, Hamad MA, van Zundert AJ, Martens EJ, Schonberger JP, de Wolf AM. Preoperative hemoglobin level as a predictor of survival after coronary artery bypass grafting: a comparison with the matched general population. Circulation. 2009;120:118-25.

33. Zindrou D, Taylor KM, Bagger JP. Preoperative haemoglobin concentration and mortality rate after coronary artery bypass surgery. Lancet. 2002;359:1747-8.

34. Ranucci M, Conti D, Castelvecchio S, Menicanti L, Frigiola A, Ballotta A, et al. Hematocrit on cardiopulmonary bypass and outcome after coronary surgery in nontransfused patients. Ann Thorac Surg. 2010;89:11-7.

35. De Santo L, Romano G, Della Corte A, de Simone V, Grimaldi F, Cotrufo M et al. Preoperative anemia in patients undergoing coronary artery bypass grafting predicts acute kidney injury. J Thorac Cardiovasc Surg. 2009;138:965-70.

36. Kazmierski J, Kowman M, Banach M, Fendler W, Okonski P, Banys A, et al. Incidence and predictors of delirium after cardiac surgery: results from the IPDACS Study. J Psychosom Res. 2010;69:179-85.

37. LaPar DJ, Hawkins RB, McMurry TL, Isbell JM, Rich JB, Speir AM, et al. Preoperative anemia versus blood transfusion: which is the culprit for worse outcomes in cardiac surgery? J Thorac Cardiovasc Surg. 2018;156:66-74.e2.

38. Paone G. Anemia, transfusion, and outcome: both are bad...does it really matter which is worse? J Thorac Cardiovasc Surg. 2018;156:75-6.

39. Loor G, Koch CG, Sabik JF III, Li L, Blackstone EH. Implications and management of anemia in cardiac surgery: current state of knowledge. J Thorac Cardiovasc Surg. 2012;144:538-46.

40. Anker SD, Kirwan BA, van Veldhuisen DJ, Filippatos G, Comin-Colet J, Ruschitzka F, et al. Effects of ferric carboxymaltose on hospitalisations and mortality rates in iron-deficient heart failure patients: an individual patient data metaanalysis. Eur J Heart Fail. 2018;20:125-33.

41. Levin A, Stevens PE, Bilous RW, Coresh J, De Francisco ALM, De Jong PE, et al Kidney disease: improving global outcomes (KDIGO) CKD work group. KDIGO 2012 clinical practice guideline for the evaluation and management of chronic kidney disease. Kidney Int Suppl. 2013;3:1-150.

42. Zhou X, Xu W, Xu Y, Qian Z. Iron supplementation improves cardiovascular outcomes in patients with heart failure. Am J Med. 2019;132:955-63.

43. Meybohm P, Westphal S, Ravn HB, Ranucci M, Agarwal S, Choorapoikayil S, et al. Perioperative anemia management as part of PBM in cardiac surgery-a narrative updated review. J Cardiothorac Vasc Anesth. 2020;34:1060-73.

44. Ellermann I, Bueckmann A, Eveslage M, Buddendick H, Latal T, Niehoff D, et al. Treating anemia in the preanesthesia assessment clinic: results of a retrospective evaluation. Anesth Analg. 2018;127:1202-10.

45. Yang Y, Li H, Li B, Wang Y, Jiang S, Jiang L. Efficacy and safety of iron supplementation for the elderly patients undergoing hip or knee surgery: a metaanalysis of randomized controlled trials. J Surg Res. 2011;171:e201-7.

46. Meybohm P, Herrmann E, Steinbicker AU, Wittmann M, Gruenewald M Fischer D, et al. Patient blood management is associated with a substantial reduction of red blood cell utilization and safe for patient's outcome: a prospective, multicenter cohort study with a noninferiority design. Ann Surg. 2016;264 203-11.

47. ten Broeke R, Bravenboer B, Smulders FJ. Iron deficiency before and after bariatric surgery: the need for iron supplementation. Neth J Med. 2013;71:412-7.

48. Ng O, Keeler BD, Mishra A, Simpson JA, Neal K, Al-Hassi HO, et al. Iron therapy for preoperative anaemia. Cochrane Database Syst Rev. 2019;12:CD011588.

49. Richards T, Baikady RR, Clevenger B, Butcher A, Abeysiri S, Chau M, et al. Preoperative intravenous iron to treat anaemia before major abdominal surgery (PREVENTT): a randomised, double-blind, controlled trial. Lancet. 2020;396: 1353-61.

50. Cladellas M, Farre N, Comin-Colet J, Gomez M, Merono O, Bosch MA, et al Effects of preoperative intravenous erythropoietin plus iron on outcome in anemic patients after cardiac valve replacement. Am J Cardiol. 2012;110:1021-6.

51. Johansson PI, Rasmussen AS, Thomsen LL. Intravenous iron isomaltoside 1000 (Monofer $(\mathrm{R})$ ) reduces postoperative anaemia in preoperatively nonanaemic patients undergoing elective or subacute coronary artery bypass graft, valve replacement or a combination thereof: a randomized double-blind placebo-controlled clinical trial (the PROTECT trial). Vox Sang. 2015;109: 257-66.

52. Chau M, Richards T, Evans C, Butcher A, Collier T, Klein A. The UK Cardiac and Vascular Surgery Interventional Anaemia Response (CAVIAR) Study: protocol for an observational cohort study to determine the impact and effect of preoperative anaemia management in cardiac and vascular surgical patients. BMJ Open. 2017;7:e014872.

53. Duce L, Cooter ML, McCartney SL, Lombard FW, Guinn NR. Outcomes in patients undergoing cardiac surgery who decline transfusion and received erythropoietin compared to patients who did not: a matched cohort study. Anesth Analg. 2018;127:490-5. 
54. Yoo YC, Shim JK, Kim JC, Jo YY, Lee JH, Kwak YL. Effect of single recombinant human erythropoietin injection on transfusion requirements in preoperatively anemic patients undergoing valvular heart surgery. Anesthesiology. 2011;115:929-37.

55. Yazicioglu L, Eryilmaz S, Sirlak M, Inan MB, Aral A, Tasoz R, et al. Recombinant human erythropoietin administration in cardiac surgery. J Thorac Cardiovasc Surg. 2001;122:741-5.

56. Padhi S, Kemmis-Betty S, Rajesh S, Hill J, Murphy MF. Guideline Development Gropu. Blood transfusion: summary of NICE guidance. BMJ. 2015;351:h5832.

57. Task Force on Patient Blood Management for Adult Cardiac Surgery of the European Association for Cardio-Thoracic Society, the European Association of Cardiothoracic A, Boer C, Meesters MI, Milojevic M, Benedetto U, et al. 2017 EACTS/EACTA guidelines on patient blood management for adult cardiac surgery. J Cardiothorac Vasc Anesth. 2018;32:88-120.

58. Gombotz H, Rehak PH, Shander A, Hofmann A. Blood use in elective surgery: the Austrian benchmark study. Transfusion. 2007;47:1468-80.

59. Gombotz H, Rehak PH, Shander A, Hofmann A. The second Austrian benchmark study for blood use in elective surgery: results and practice change. Transfusion. 2014;54:2646-57.

60. Cabana MD, Rand CS, Powe NR, Wu AW, Wilson MH, Abboud PA, et al. Why don't physicians follow clinical practice guidelines? A framework for improvement. JAMA. 1999;282:1458-65.

61. Munoz M, Gomez-Ramirez S, Kozek-Langeneker S, Shander A, Richards T, Pavia J, et al. 'Fit to fly': overcoming barriers to preoperative haemoglobin optimization in surgical patients. Br J Anaesth. 2015;115:15-24.

62. Ad N, Luc JGY, Nguyen TC. COVID-19 North American Cardiac Surgery Survey working group. Cardiac surgery in North America and coronavirus disease 2019 (COVID-19): regional variability in burden and impact. J Thorac Cardiovasc Surg. June 2, 2020 [Epub ahead of print].

63. Chikwe J, Gaudino M, Hameed I, Robinson NB, Bakaeen FG, Menicanti L, et al. Committee recommendations for resuming cardiac surgery activity in the SARSCoV-2 era: guidance from an international cardiac surgery consortium. Ann Thorac Surg. 2020;110:725-32.

64. Ray AA, Buth KJ, Sullivan JA, Johnstone DE, Hirsch GM. Waiting for cardiac surgery: results of a risk-stratified queuing process. Circulation. 2001;104:I92-8.

65. Sobolev BG, Fradet G, Kuramoto L, Rogula B. The occurrence of adverse events in relation to time after registration for coronary artery bypass surgery: a population-based observational study. J Cardiothorac Surg. 2013; 8:74.

66. Rashid M, Ludman PF, Mamas MA. British Cardiovascular Intervention Society registry framework: a quality improvement initiative on behalf of the National Institute of Cardiovascular Outcomes Research (NICOR). Eur Heart J. 2019;5: 292-7.

67. Morgan CD, Sykora K, Naylor CD. Analysis of deaths while waiting for cardiac surgery among 29,293 consecutive patients in Ontario, Canada. The Steering Committee of the Cardiac Care Network of Ontario. Heart. 1998;79:345-9.

68. Rexius H, Brandrup-Wognsen G, Oden A, Jeppsson A. Mortality on the waiting list for coronary artery bypass grafting: incidence and risk factors. Ann Thorac Surg. 2004;77:769-74; discussion 74-5.

69. Malaisrie SC, McDonald E, Kruse J, Li Z, McGee EC Jr, Abicht TO, et al. Mortality while waiting for aortic valve replacement. Ann Thorac Surg. 2014;98: 1564-70; discussion 70-1.

70. Mabry C, Perelman S, Kim JT, Blitz JD. Implementation of a preoperative anemia clinic utilizing a minimal staffing model. A A Pract. 2020;14:90-4.

71. Warner MA, Shore-Lesserson L, Shander A, Patel SY, Perelman SI, Guinn NR. Perioperative anemia: prevention, diagnosis, and management throughout the spectrum of perioperative care. Anesth Analg. 2020;130:1364-80.

72. Munoz M, Gomez-Ramirez S, Bhandari S. The safety of available treatment options for iron-deficiency anemia. Expert Opin Drug Saf. 2018; 17:149-59.

73. Gomez-Ramirez S, Bisbe E, Shander A, Spahn DR, Munoz M. Management of perioperative iron deficiency anemia. Acta Haematol. 2019;142:21-9.

74. Auerbach M, Adamson JW. How we diagnose and treat iron deficiency anemia. Am J Hematol. 2016;91:31-8.

75. Auerbach M, Deloughery T. Single-dose intravenous iron for iron deficiency: a new paradigm. Hematology Am Soc Hematol Educ Program. 2016;2016: 57-66.

76. Klein AA, Chau M, Yeates JA, Collier T, Evans C, Agarwal S, et al. Preoperative intravenous iron before cardiac surgery: a prospective multicentre feasibility study. Br J Anaesth. 2020;124:243-50.

Key Words: COVID-19, preoperative anemia, cardiac, $\mathrm{RBC}$ transfusion, allogeneic 